\title{
A DISSOCIAÇÃO ENTRE QUANTIDADE E QUALIDADE NA PRODUÇÃO GEOMORFOLÓGICA BRASILEIRA NO SÉCULO XXI
}

\author{
THE DISSOCIATION BETWEEN QUANTITY AND QUALITY IN BRAZILIAN \\ GEOMORPHOLOGICAL PRODUCTION IN THE BEGIN OF XXI CENTURY
}

\begin{abstract}
André Augusto Rodrigues Salgado
Geógrafo e Mestre em Geografia pela Universidade Federal de Minas Gerais

Doutor em Evolução Crustal pela Universidade Federal de Ouro Preto

Doutor em Geociências pela Université d’Aix-Marseille na França

Professor Associado IV do Departamento de Geografia da Universidade Federal de Minas Gerais, Brasil aarsalgadoufmg@gmail.com
\end{abstract}

\author{
Breno Ribeiro Marent \\ Doutor em Geografia pela UFMG, Brasil \\ Consultor Ambiental.
}

\begin{abstract}
Resumo
Algumas características da Ciência de um país podem ser identificadas pela sua produção científica. O presente trabalho investiga a evolução da relação entre quantidade e qualidade da produção brasileira em Geomorfologia em periódicos. Isto foi feito através de dados apresentados pelo International Science Ranking, que acompanha as métricas de publicação e citação por país e por área do saber. Os resultados obtidos indicaram que entre 2010 e 2019, a produção científica brasileira em Geomorfologia mais do que triplicou. Entretanto, mesmo com mais artigos publicados para serem citados, a evolução no ranking de citações foi pequena. Este fato indica haver uma dissociação entre quantidade e qualidade da produção geomorfológica brasileira no período considerado. Não foi possível determinar com exatidão por qual razão ocorreu essa dissociação. Entretanto, três hipóteses foram consideradas como podendo ter agido em conjunto: o rápido crescimento do número de pesquisadores em Geografia no Brasil, o crescente custo financeiro para realização de pesquisas com maior impacto e o grande número de periódicos geográficos nacionais bem avaliados no sistema Qualis CAPES Geografia.
\end{abstract}

Palavras-chave: Geomorfologia; Ciência; Artigo científico; Citações.

\begin{abstract}
Many of the characteristics of Science in a country can be identified by its scientific production. This work investigates the evolution of the relationship between quantity and quality of Brazilian production in Geomorphology published in scientific journals. This was done based on the data presented by the International Science Ranking, which monitors the metrics of scientific publication and citation by country and by field of knowledge. The
\end{abstract}


results obtained indicated that over the period between 2010 and 2019, the Brazilian production in Geomorphology published more than tripled. However, even with many more articles published to be cited, the evolution of the country in the world ranking of citations was small. This indicates that there is a dissociation between quantity and quality of Brazilian geomorphological production in the period considerate. It was not possible to determine exactly why this dissociation occurred. However, three hypotheses were considered, and they can have acted together: the rapid growth in the number of researchers in Geography in Brazil, the growing of financial cost to carry out research with good impact and the large number of national geographic scientific journals that been well evaluated in the Qualis CAPES Geography system.

Keywords: Geomorphology; Science; Scientific paper; Citation.

\section{INTRODUÇÃO}

A Geomorfologia é uma área do conhecimento que, em termos quantitativos, aparenta ter se desenvolvido muito rapidamente ao longo do início do século XXI no Brasil. O crescimento do número de participantes nos simpósios nacionais de Geomorfologia (SINAGEO) e de artigos na Revista Brasileira de Geomorfologia exemplificam muito bem essa aparente tendência de expansão. Entretanto, um crescimento em termos quantitativos nem sempre é acompanhado por uma melhora qualitativa. Pelo contrário: quando se cresce muito rapidamente do ponto de vista quantitativo, geralmente, em termos qualitativos, ocorre uma perda.

Vale ressaltar que não há trabalhos que tentem avaliar se realmente houve um crescimento quantitativo da produção de conhecimento geomorfológico no Brasil. Tampouco há pesquisas que avaliem a qualidade do que, em termos de conhecimento geomorfológico, é produzido no território nacional. Talvez isto ocorra pela latente dificuldade de se mensurar a qualidade científica de uma publicação. Neste sentido, salvo aqueles trabalhos aplicados que estão diretamente ligados à produção técnica e que podem ser avaliados pelo sucesso instrumental que produzem, o número de citações foi o único caminho encontrado pela Ciência para mensurar a qualidade das publicações. Entende-se que documentos muito citados foram mais úteis para o progresso do conhecimento do que aqueles que foram pouco utilizados. Mas mesmo este tipo de avaliação apresenta problemas. Há áreas do saber como, por exemplo a Medicina, que naturalmente geram muitas citações e outras que, também naturalmente, geram menos. Logo, é normal que um trabalho mediano na área médica seja mais citado do que, por exemplo, um bom nas Geociências. A imensa diferença entre o fator de impacto e o índice $\mathrm{H}$ dos periódicos destas duas áreas deixa este fato bem evidente (Journal Citation 
Reports, 2020; Google Acadêmico, 2021). Além disto, as diferentes áreas do conhecimento possuem características próprias e variações de meia-vida. Por características próprias entende-se, neste caso, o tipo de publicação que é valorizado. Nas áreas de saúde, das exatas e da natureza, valoriza-se o artigo em periódico. Por sua vez, nas humanas e sociais o livro adquire grande importância. Já a meia-vida refere-se ao tempo médio que um documento será citado após publicado. Comparando novamente a Medicina com as Geociências, um documento da área de Medicina tende a ter meia vida muito mais curta do que um de Geociências (Journal Citation Reports, 2020; Google Acadêmico, 2021). Isto significa que os documentos de Medicina em comparação com os de Geociências, embora sejam mais citados, tendem a ser por menos tempo. Logo, um documento típico da área de Medicina será muito citado nos dois primeiros anos posteriores a sua publicação. Depois disso tenderá a ser cada vez menos citado e mais esquecido. Já nas Geociências este prazo é um pouco maior e há documentos que só atingem seu auge em termos de citações cinco ou mais anos depois de publicados.

O conjunto de observações acima apresentado demonstra como é difícil mensurar a qualidade científica de um documento, principalmente entre diferentes áreas do conhecimento. Entretanto, é inegável que, dentro de cada área do saber, os documentos mais citados são aqueles que determinaram a direção pelo qual o conhecimento avançou. Foram eles que causaram maior impacto na comunidade científica e que mais influenciaram os pesquisadores em seus trabalhos. Sendo assim, apesar de suas inúmeras limitações, o número de citações permite se ter uma ideia qualitativa da produção científica.

Neste contexto, o presente trabalho avalia se realmente houve um crescimento quantitativo da produção de conhecimento geomorfológico no Brasil neste início de século XXI e, se sim, como evoluiu a relação entre quantidade e qualidade dos artigos científicos publicados durante este processo de expansão. Esta evolução é analisada no contexto das tendências da produção continental e global de conhecimento geomorfológico, bem como da Ciência brasileira como um todo. Os dados para análise foram obtidos através da plataforma global Internacional Science Ranking para o período entre 2010 e 2019. Parte-se de um primeiro pressuposto que a plataforma global Internacional Science Ranking, ao acompanhar as publicações e citações em todos os periódicos que possuem número de $\mathrm{DOI}$, é um bom instrumento para se levantar a produção nacional de Geomorfologia. Em paralelo, há um segundo pressuposto: para que não haja perda de 
qualidade, o crescimento quantitativo da produção brasileira deve ser seguido de um proporcional crescimento das citações no âmbito da plataforma.

\section{PROCEDIMENTOS MEDOTODOLÓGICOS}

Para avaliar a evolução quantitativa e qualitativa da produção do conhecimento geomorfológico no Brasil foram levantados dados do Internacional Science Ranking publicado pela Scimago Journal \& Country Rank (SJR, 2021). Tais dados foram obtidos considerando-se a posição de todos os países do mundo em número de publicações e citações entre 2010 e 2019. O ano de 2010 como início justifica-se em virtude de o Brasil estar colocado na mesma posição para a Geomorfologia no ranking mundial, tanto para o número de publicações, quanto de citações, podendo ser considerado como marco zero para a análise deste estudo. O de 2019 justifica-se por ser o último em que o Scimago Journal \& Country Rank (SJR, 2021) apresenta dados. Por outro lado, dez anos (20102019) é um período que já permite construir uma análise segura das tendências apresentadas.

Em um primeiro momento foram comparadas as evoluções no número de publicações e citações de documentos brasileiros no ranking mundial para a "Geomorfologia", "Geociências" e "Ciência brasileira (todas as áreas das ciências juntas)". Os dados dessa etapa para a "Geomorfologia" foram obtidos a partir da seleção da categoria "Earth-Surface Processes" na área de "Earth and Planetary Sciences". Para as "Geociências" foram utilizados os dados de toda a área "Earth and Planetary Sciences". Já para "Ciência brasileira" foram consideradas todas as áreas do saber (All subject areas). Os dados foram tabelados e gerados gráficos de evolução da produção e evolução das citações de documentos (artigos) brasileiros no ranking mundial, comparando a "Geomorfologia", "Geociências" e "Ciência brasileira". A partir dos dados foram produzidos gráficos comparativos da evolução do Brasil em termos de produção de documentos científicos e de citações no ranking mundial. Para além dos dados brutos apresentados no site (SJR, 2021), foi elaborado um índice aqui chamado de índice alpha (a), caracterizado pela seguinte fórmula (1):

Fórmula (1)

$\boldsymbol{\alpha}=$ Posição no Ranking Mundial de Produção de Documentos / Posição no Ranking Mundial de Citações 
O índice $\boldsymbol{\alpha}$ permite uma comparação entre quantidade e qualidade dos documentos publicados no ranking mundial, sendo a maneira encontrada para se verificar a evolução entre o número de documentos publicados e o de citações. Tal abordagem seguiu o pressuposto de que países que ocupem a mesma posição no ranking mundial de produção de documentos e de citações, apresentam índice $\boldsymbol{\alpha}=1,00$. Se um país tem melhores posições no ranking de produção de documentos do que no de citações seu índice $\boldsymbol{\alpha}$ será obrigatoriamente menor que 1,00. Se for o contrário, seu índice $\boldsymbol{\alpha}$ será obrigatoriamente maior que 1,00. Por exemplo: se um país ocupa a $10^{a}$ posição no mundo em termos de produção de documentos e a $20^{\mathrm{a}}$ no de citações, $\boldsymbol{\alpha}=10 / 20=0,50$. Já se ele for $\circ 20^{\circ}$ no ranking de produção de documentos e o $10^{\circ}$ no de citações, $\boldsymbol{\alpha}=20 / 10=$ 2,00. Logo, índices superiores a 1,00 indicam países que, no ranking mundial, se destacam mais pela qualidade de sua produção do que pela quantidade. Já países com índices inferiores a 1,00 se destacam mais pela quantidade do que pela qualidade.

Além da comparação realizada entre a Geomorfologia com as Geociências e todas as áreas da Ciência no Brasil, foi também efetivada a análise, apenas para a Geomorfologia, com os países mais produtivos da América Latina: Argentina, Chile, Colômbia e México, pois estes exibem um contexto regional, social, cultural e econômico mais próximo ao do Brasil. Esta comparação objetivou verificar se as tendências apresentadas pela geomorfologia brasileira eram compartilhadas pelos seus vizinhos latino-americanos. Isto também foi feito para os países que em 2010 ocupavam uma posição no ranking quantitativo de produção de documentos geomorfológicos semelhantes ao do Brasil: Suécia (duas posições acima), Noruega (uma posição acima), Bélgica (uma abaixo) e Áustria (duas abaixo). Esta segunda comparação objetivou verificar se as tendências apresentadas pelo Brasil eram na verdade as de um grupo de países que tinham produção similar à brasileira em 2010. Tais comparações são importantes, pois, em uma situação hipotética, imagine-se que o Brasil tenha perdido muitas posições no ranking. Esta situação pode ser resultado de um problema interno do Brasil ou, em função de um grupo de países, asiáticos por exemplo, terem crescido de forma muito acelerada. Se for um problema interno brasileiro, não será compartilhado pelos seus vizinhos latino-americanos, nem pelos países que em 2010 ocupavam posição semelhante no ranking mundial. Entretanto, se a queda na posição mundial ocorreu em função de um crescimento acelerado de um outro grupo de países, a queda no ranking não ficaria restrita ao Brasil. 


\section{RESULTADOS}

A Tabela 1 mostra que o Brasil, ao longo dos dez anos que separam 2010 e 2019, expandiu enormemente sua produção de documentos científicos geomorfológicos. Esta produção mais do que triplicou nos dez anos analisados, mas a expansão não foi acompanhada por um crescimento paralelo em termos de citações recebidas. Pelo contrário: salvo exceções, em 2010 os documentos geomorfológicos brasileiros receberam mais citações do que nos anos posteriores. Entretanto, há de ser considerado que a comparação entre produção e citações não pode ser direta, pois os documentos publicados nos anos mais recentes tiveram menos tempo para serem citados e, sendo assim, tendem naturalmente a apresentar menos citações. Logo, a única forma de saber se o número de citações recebidas acompanhou adequadamente o crescimento da produção é verificar a posição do país no ranking de citações. Neste sentido, se em 2010 o Brasil era o $18^{\circ}$ país que mais produzia documentos geomorfológicos, em 2019 ele se tornou o $10^{\circ}$ (Tabela 1 e Figura 1 ).

Tabela 1: Situação da Geomorfologia, das Geociências e da Ciência brasileira. nos rankings mundiais de produção de documentos e de citações entre 2010-2019.

\begin{tabular}{|c|c|c|c|c|c|c|c|c|c|c|c|}
\hline & Ano & 2010 & 2011 & 2012 & 2013 & 2014 & 2015 & 2016 & 2017 & 2018 & 2019 \\
\hline \multirow{5}{*}{$\begin{array}{l}\frac{\pi}{0} \\
\text { o0 } \\
0 \\
0 \\
0 \\
0 \\
0 \\
0\end{array}$} & № Produções & 162 & 257 & 205 & 324 & 307 & 326 & 505 & 459 & 516 & 576 \\
\hline & Posição Produções & 18 & 15 & 18 & 14 & 15 & 15 & 12 & 12 & 12 & 10 \\
\hline & № Citações & 4832 & 5109 & 3803 & 5605 & 3594 & 3363 & 3378 & 1958 & 1142 & 318 \\
\hline & Posição Citações & 18 & 18 & 19 & 18 & 18 & 17 & 17 & 18 & 16 & 16 \\
\hline & Índice alpha & 1,0 & 0,8 & 0,9 & 0,8 & 0,8 & 0,9 & 0,7 & 0,7 & 0,8 & 0,6 \\
\hline \multirow{5}{*}{ 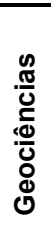 } & № Produções & 1791 & 1948 & 2015 & 2464 & 2715 & 2694 & 3247 & 3193 & 3565 & 3875 \\
\hline & Posição Produções & 15 & 15 & 15 & 15 & 14 & 15 & 15 & 15 & 16 & 14 \\
\hline & $N^{\circ}$ Citações & 29832 & 33520 & 28904 & 34141 & 28236 & 28729 & 33394 & 19967 & 11912 & 2553 \\
\hline & Posição Citações & 21 & 22 & 21 & 20 & 21 & 17 & 16 & 16 & 17 & 17 \\
\hline & Índice alpha & 0,7 & 0,7 & 0,7 & 0,8 & 0,7 & 0,9 & 0,9 & 0,9 & 0,9 & 0,8 \\
\hline \multirow{5}{*}{ 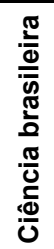 } & No Produções & 51020 & 55476 & 61509 & 64835 & 68398 & 70484 & 75160 & 79335 & 83839 & 84887 \\
\hline & Posição Produções & 13 & 13 & 13 & 13 & 13 & 13 & 14 & 14 & 14 & 14 \\
\hline & $\mathbf{N}^{\circ}$ Citações & 761054 & 764079 & 762629 & 728612 & 669789 & 616442 & 529956 & 377940 & 200861 & 45929 \\
\hline & Posição Citações & 17 & 17 & 17 & 17 & 16 & 16 & 16 & 16 & 16 & 17 \\
\hline & Índice alpha & 0,8 & 0,8 & 0,8 & 0,8 & 0,8 & 0,8 & 0,9 & 0,9 & 0,9 & 0,8 \\
\hline
\end{tabular}

Ou seja, o crescimento da produção de documentos geomorfológicos no Brasil foi muito maior que a média mundial, pois o fez saltar oito posições no ranking global. Entretanto, este salto não ocorreu em termos qualitativos, pois o Brasil permaneceu praticamente estável no ranking de citações. Em 2010 era também o $18^{\circ}$ país mais citado, fato que mostra, para a época, um equilíbrio entre quantidade e qualidade da produção. 
Porém, em 2019 era apenas o $16^{\circ}$ no ranking de citações. Isto evidencia que o crescimento quantitativo não foi acompanhado de um qualitativo, pois proporcionalmente aos outros países do mundo, os documentos brasileiros da área de Geomorfologia foram muito menos citados do que deveriam ter sido caso o Brasil tivesse mantido o padrão de 2010 (Figura 1). Foram muito mais documentos para a quantidade de citações. Logo, no geral, houve uma perda qualitativa.

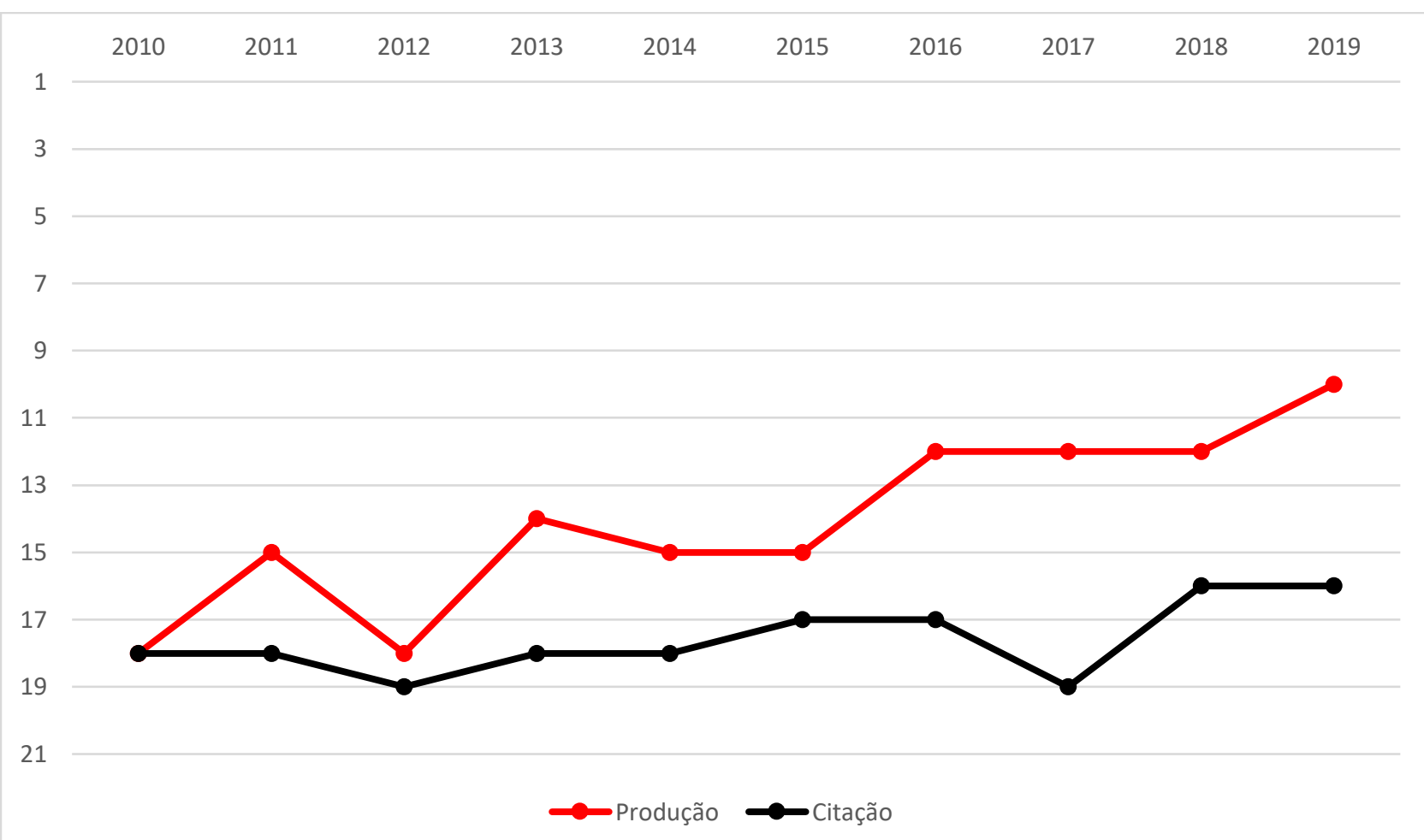

Figura 1: Evolução do Brasil em termos de produção de documentos e de citações no ranking mundial para a área de Geomorfologia.

O interessante é que este crescimento quantitativo na produção de documentos da Geomorfologia brasileira não pode ser considerado normal. Nem a Ciência brasileira como um todo, nem a grande área das Geociências, galgaram posições tão rapidamente no ranking mundial (Tabela 1 e Figura 2). Pelo contrário: as Geociências e a Ciência brasileira como um todo permaneceram praticamente estáveis em suas posições no ranking mundial de produção ao longo destes últimos dez anos (Figura 2). E esta estabilidade se prolongou para o ranking de citações, pois a posição do Brasil para todas as áreas do saber praticamente não se modificou ao longo destes últimos dez anos e, no caso da Geociências, até melhorou um pouco (Tabela 1 e Figura 2). Isto significa que enquanto a Geomorfologia brasileira tinha um decréscimo no seu índice $\boldsymbol{\alpha}$, a Ciência brasileira e a grande área das Geociências apresentaram certa estabilidade (Figura 3). 
Considerando os extremos de 2010 e 2019, pode-se mesmo afirmar que elas ostentaram leve melhora em seus índices $\boldsymbol{\alpha}$ (Figura 3). Ou seja, a Geomorfologia brasileira não exibiu comportamento semelhante ao exibido pela Ciência brasileira como um todo e pelas Geociências, pois enquanto seu índice $\boldsymbol{\alpha}$ decresceu de forma praticamente constante, o das Geociências e da Ciência brasileira permaneceram bem mais estáveis, apresentando até uma leve melhora (Figura 3).

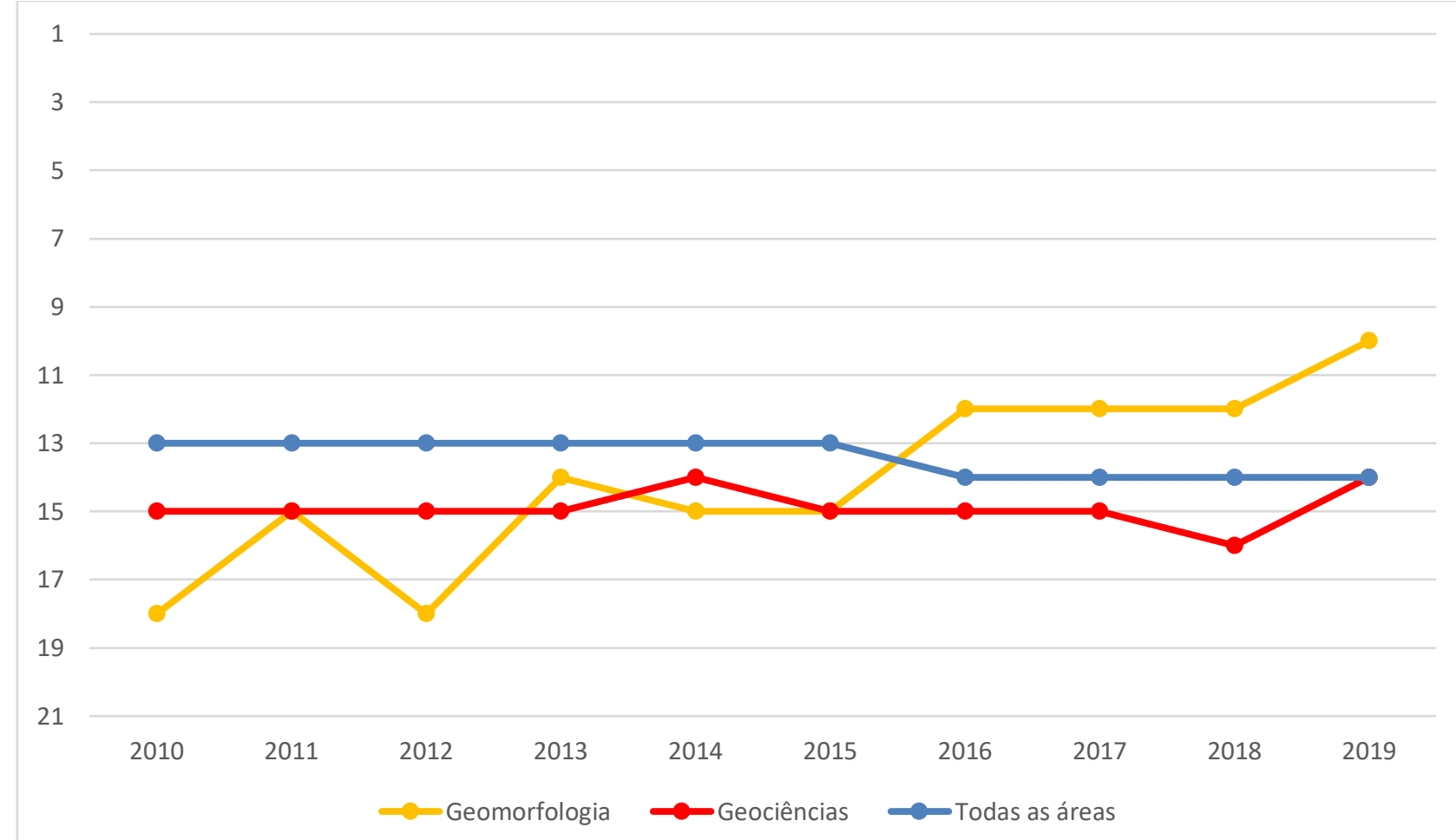

Figura 2: Evolução da produção de documentos brasileiros no ranking mundial para Geomorfologia, Geociências e Ciência brasileira.

Considerando que o elevado crescimento quantitativo da Geomorfologia brasileira não encontra correspondência nem na Ciência como um todo, nem nas Geociências brasileiras, torna-se necessário avaliar se esta expansão é um fenômeno da área do saber na América Latina. Mas também não o é, pois a expansão quantitativa da Geomorfologia brasileira foi muito superior à dos países latino-americanos que tem alguma relevância no ranking mundial: Argentina, Chile, Colômbia e México (Tabela 2 e Figura 4). Além disso, a evolução do índice $\boldsymbol{\alpha}$ do Brasil é a pior entre os cinco países (Tabela 2 e Figura 5). Na verdade, todos estes países pioraram neste índice nos últimos dez anos. A exceção ocorreu com a Argentina que se manteve estacionária, porém mantendo o índice $\boldsymbol{\alpha}$ abaixo de 1,00 na maior parte do período analisado. Entretanto, a piora no Brasil foi a mais acentuada (Figura 5). 
1,20

1,00

0,80

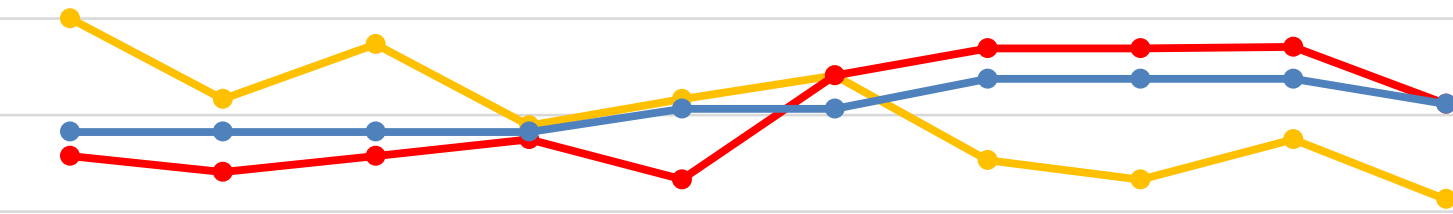

0,60

0,00
2010
$20112012 \quad 2013$
2014
2015
2016
2017
2018
2019
Geomorfologia -Geociências - $\quad$ Todas as áreas

Figura 3: Índice $\boldsymbol{\alpha}$ (relação produção/citações) para documentos brasileiros no ranking mundial para Geomorfologia, Geociências e Ciência brasileira.

Tabela 2: Situação nos rankings mundiais de Geomorfologia de produção de documentos e de citações entre 2010-2019 para os principais países produtores de conhecimento geomorfológico da América Latina.

\begin{tabular}{|c|c|c|c|c|c|c|c|c|c|c|c|}
\hline & Ano & 2010 & 2011 & 2012 & 2013 & 2014 & 2015 & 2016 & 2017 & 2018 & 2019 \\
\hline \multirow{5}{*}{$\begin{array}{l}\overline{\bar{g}} \\
\frac{\pi}{\bar{n}} \\
\overline{\mathbf{m}}\end{array}$} & NNo Produções $^{\circ}$ & 162 & 257 & 205 & 324 & 307 & 326 & 505 & 459 & 516 & 576 \\
\hline & Posição Produções & 18 & 15 & 18 & 14 & 15 & 15 & 12 & 12 & 12 & 10 \\
\hline & $\mathrm{N}^{\circ}$ Citações & 4832 & 5109 & 3803 & 5605 & 3594 & 3363 & 3378 & 1958 & 1142 & 318 \\
\hline & Posição Citações & 18 & 18 & 19 & 18 & 18 & 17 & 17 & 18 & 16 & 16 \\
\hline & Índice alpha & 1,0 & 0,8 & 0,9 & 0,8 & 0,8 & 0,9 & 0,7 & 0,7 & 0,8 & 0,6 \\
\hline \multirow{5}{*}{ 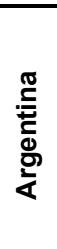 } & $\mathbf{N}^{\circ}$ Produções & 132 & 149 & 170 & 200 & 162 & 241 & 209 & 205 & 230 & 283 \\
\hline & Posição Produções & 24 & 26 & 24 & 22 & 25 & 18 & 23 & 22 & 21 & 18 \\
\hline & $\mathrm{N}^{\circ}$ Citações & 2825 & 2507 & 2454 & 3081 & 1817 & 2454 & 1389 & 893 & 580 & 181 \\
\hline & Posição Citações & 26 & 25 & 29 & 24 & 30 & 21 & 28 & 25 & 25 & 20 \\
\hline & Índice alpha & 0,9 & 1,0 & 0,8 & 0,9 & 0,8 & 0,9 & 0,8 & 0,9 & 0,8 & 0,9 \\
\hline \multirow{5}{*}{ 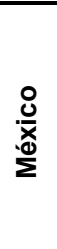 } & $\mathbf{N}^{\circ}$ Produções & 117 & 88 & 106 & 108 & 80 & 107 & 131 & 162 & 159 & 188 \\
\hline & Posição Produções & 28 & 35 & 33 & 32 & 37 & 34 & 34 & 25 & 28 & 26 \\
\hline & $\mathrm{N}^{\circ}$ Citações & 2754 & 1732 & 2250 & 1611 & 790 & 1495 & 954 & 624 & 350 & 109 \\
\hline & Posição Citações & 27 & 33 & 30 & 36 & 42 & 31 & 36 & 34 & 34 & 34 \\
\hline & Índice alpha & 1,0 & 1,1 & 1,1 & 0,9 & 0,9 & 1,1 & 0,9 & 0,7 & 0,8 & 0,8 \\
\hline \multirow{5}{*}{ 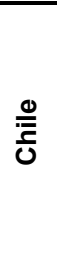 } & $\mathbf{N}^{\circ}$ Produções & 56 & 78 & 85 & 101 & 95 & 123 & 123 & 142 & 149 & 150 \\
\hline & Posição Produções & 39 & 38 & 37 & 35 & 33 & 32 & 35 & 28 & 31 & 29 \\
\hline & $\mathrm{N}^{\circ}$ Citações & 1497 & 1545 & 1324 & 3052 & 1153 & 1725 & 940 & 632 & 542 & 88 \\
\hline & Posição Citações & 36 & 36 & 38 & 25 & 37 & 29 & 37 & 33 & 28 & 39 \\
\hline & Índice alpha & 1,1 & 1,1 & 1,0 & 1,4 & 0,9 & 1,1 & 0,9 & 0,8 & 1,1 & 0,7 \\
\hline \multirow{5}{*}{$\begin{array}{l}\frac{\pi}{0} \\
\frac{8}{0} \\
\frac{0}{0} \\
0\end{array}$} & $\mathbf{N}^{\circ}$ Produções & 27 & 22 & 26 & 34 & 28 & 29 & 50 & 38 & 46 & 72 \\
\hline & Posição Produções & 48 & 53 & 50 & 51 & 56 & 58 & 50 & 53 & 54 & 39 \\
\hline & $\mathrm{N}^{\circ}$ Citações & 969 & 494 & 932 & 639 & 790 & 224 & 159 & 157 & 166 & 39 \\
\hline & Posição Citações & 42 & 49 & 40 & 45 & 42 & 65 & 67 & 57 & 46 & 50 \\
\hline & Índice alpha & 1,1 & 1,1 & 1,3 & 1,1 & 1,3 & 0,9 & 0,7 & 0,9 & 1,2 & 0,8 \\
\hline
\end{tabular}


Caderno de Geografia (2022) v.32, n.68

ISSN 2318-2962

DOI 10.5752/p.2318-2962.2022v32n.68p.270

\section{0}

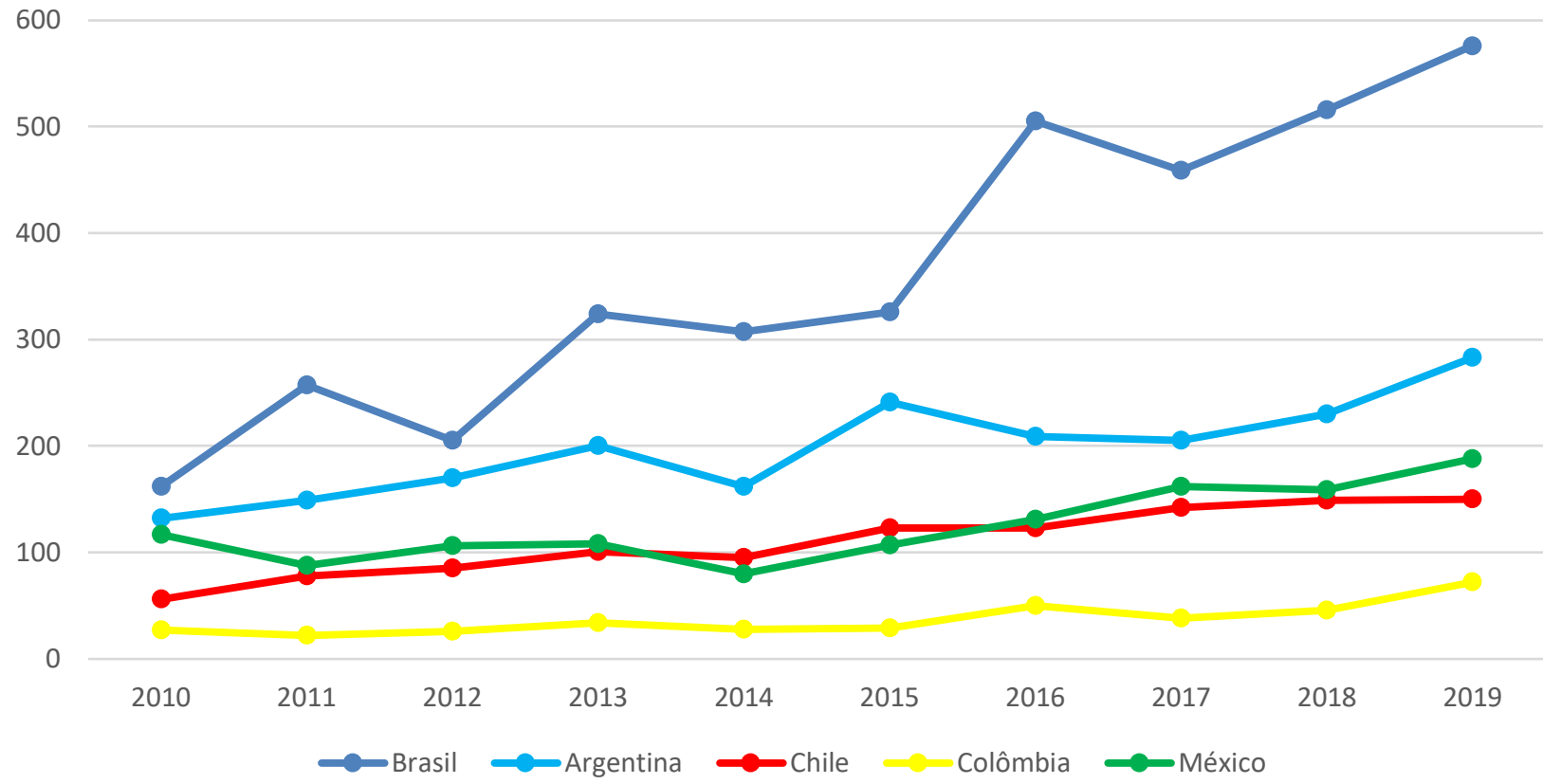

Figura 4: Evolução da produção de documentos científicos de Geomorfologia para os países mais produtivos da América Latina: Argentina, Brasil, Chile, Colômbia e México.

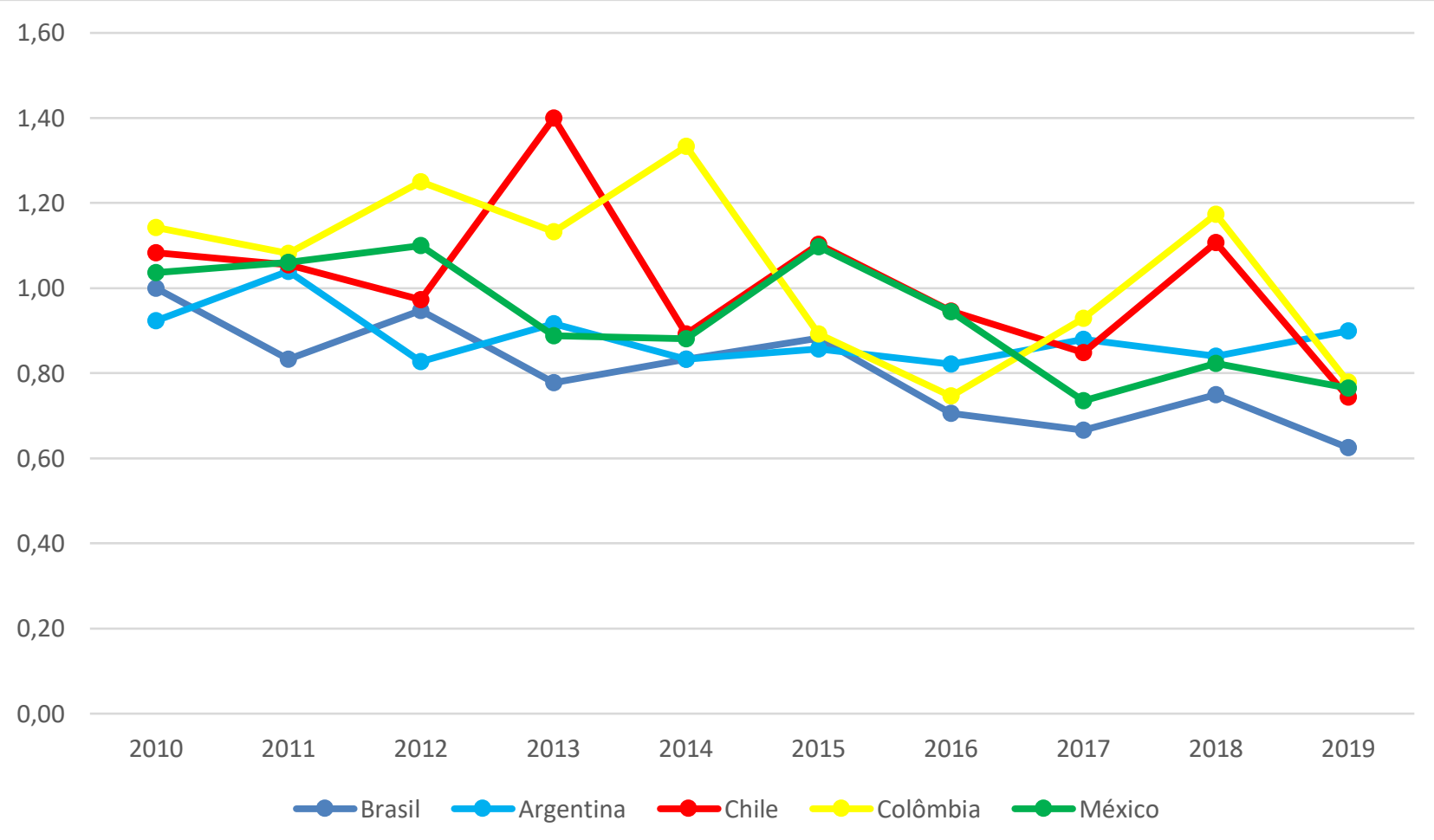

Figura 5: Evolução do índice $\boldsymbol{\alpha}$ (relação produção/citações) no ranking mundial de Geomorfologia para os países mais produtivos da América Latina: Argentina, Brasil, Chile, Colômbia e México. 
O crescimento quantitativo da produção da Geomorfologia brasileira nos últimos dez anos também não pode ser considerado um fenômeno relacionado aos países que ocupavam posição semelhante no ranking mundial. Em 2010 o Brasil era o país com a $18^{a}$ maior produção. Suécia era $\circ 16^{\circ}$, Noruega o $17^{\circ}$, Bélgica $\circ 19^{\circ}$ e Áustria o $20^{\circ}$ (Tabela 3).

Tabela 3: Situação nos rankings mundiais de Geomorfologia na produção de documentos e de citações entre 2010-2019 para os principais países que em 2010 ocupavam posições semelhantes à do Brasil.

\begin{tabular}{|c|c|c|c|c|c|c|c|c|c|c|c|}
\hline & Ano & 2010 & 2011 & 2012 & 2013 & 2014 & 2015 & 2016 & 2017 & 2018 & 2019 \\
\hline \multirow{5}{*}{$\begin{array}{l}\overline{\bar{g}} \\
\overline{\frac{\pi}{5}} \\
\bar{m}\end{array}$} & $\mathbf{N}^{\circ}$ Produções & 162 & 257 & 205 & 324 & 307 & 326 & 505 & 459 & 516 & 576 \\
\hline & Posição Produções & 18 & 15 & 18 & 14 & 15 & 15 & 12 & 12 & 12 & 10 \\
\hline & $N^{\circ}$ Citações & 4832 & 5109 & 3803 & 5605 & 3594 & 3363 & 3378 & 1958 & 1142 & 318 \\
\hline & Posição Citações & 18 & 18 & 19 & 18 & 18 & 17 & 17 & 18 & 16 & 16 \\
\hline & Índice alpha & 1,0 & 0,8 & 0,9 & 0,8 & 0,8 & 0,9 & 0,7 & 0,7 & 0,8 & 0,6 \\
\hline \multirow{5}{*}{ 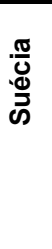 } & $\mathbf{N}^{\circ}$ Produções & 212 & 204 & 250 & 262 & 284 & 286 & 312 & 271 & 284 & 242 \\
\hline & Posição Produções & 16 & 17 & 15 & 16 & 16 & 16 & 16 & 18 & 20 & 20 \\
\hline & $\mathrm{N}^{\circ}$ Citações & 7314 & 5532 & 6217 & 6290 & 6378 & 4969 & 3534 & 2163 & 1125 & 217 \\
\hline & Posição Citações & 14 & 16 & 14 & 17 & 14 & 13 & 15 & 17 & 17 & 18 \\
\hline & Índice alpha & 1,1 & 1,1 & 1,1 & 0,9 & 1,1 & 1,2 & 1,1 & 1,1 & 1,2 & 1,1 \\
\hline \multirow{5}{*}{ 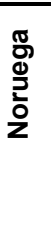 } & № Produções & 168 & 176 & 225 & 258 & 214 & 241 & 271 & 280 & 294 & 261 \\
\hline & Posição Produções & 17 & 19 & 16 & 17 & 19 & 19 & 20 & 17 & 19 & 19 \\
\hline & No Citações & 5823 & 5278 & 5682 & 10227 & 4590 & 4880 & 3412 & 2967 & 1475 & 323 \\
\hline & Posição Citações & 16 & 17 & 16 & 12 & 16 & 14 & 16 & 11 & 12 & 14 \\
\hline & Índice alpha & 1,1 & 1,1 & 1,0 & 1,4 & 1,2 & 1,4 & 1,3 & 1,5 & 1,6 & 1,4 \\
\hline \multirow{5}{*}{$\frac{\mathbb{J}}{\frac{\mathbb{6}}{\mathbb{D}}}$} & NNo Produções & 160 & 173 & 196 & 200 & 188 & 223 & 197 & 231 & 206 & 197 \\
\hline & Posição Produções & 19 & 20 & 19 & 21 & 23 & 21 & 25 & 21 & 22 & 23 \\
\hline & $\mathbf{N}^{\circ}$ Citações & 5877 & 4940 & 5907 & 5342 & 3392 & 3236 & 2061 & 1744 & 922 & 167 \\
\hline & Posição Citações & 15 & 20 & 15 & 19 & 20 & 19 & 21 & 19 & 18 & 22 \\
\hline & Índice alpha & 1,3 & 1,0 & 1,3 & 1,1 & 1,2 & 1,1 & 1,2 & 1,1 & 1,2 & 1,0 \\
\hline \multirow{5}{*}{ 吾 } & No Produções & 148 & 163 & 166 & 222 & 199 & 232 & 235 & 187 & 191 & 167 \\
\hline & Posição Produções & 20 & 23 & 25 & 20 & 20 & 20 & 21 & 23 & 24 & 27 \\
\hline & $\mathbf{N}^{\circ}$ Citações & 3845 & 5552 & 4335 & 6532 & 3475 & 3291 & 2369 & 1504 & 840 & 161 \\
\hline & Posição Citações & 21 & 15 & 18 & 16 & 19 & 18 & 19 & 20 & 20 & 23 \\
\hline & Índice alpha & 1,0 & 1,5 & 1,4 & 1,3 & 1,1 & 1,1 & 1,1 & 1,2 & 1,2 & 1,2 \\
\hline
\end{tabular}

Nenhum destes quatro países expandiu tão rapidamente sua produção quanto o Brasil (Figura 6), bem como não teve um decréscimo acentuado do índice a (Figura 7). Na verdade, além do Brasil, o único entre estes países que teve decréscimo qualitativo foi a Bélgica, mas este não foi muito acentuado e, em nenhum momento, fez com que o país tivesse índice $\boldsymbol{\alpha}$ abaixo de 1,00 , pontuação, fato que significa um perfeito equilíbrio entre quantidade e qualidade no ranking mundial. Ou seja, a Bélgica, mesmo tendo piorado um pouco, ainda apresenta uma produção que se destaca mais pela sua qualidade do que 
pela quantidade. A Suécia se manteve estável no índice $\boldsymbol{\alpha}$ com qualidade superior à quantidade e Áustria e Noruega apresentaram melhoras significativas neste índice, fato que significa que evoluíram ao longo dos últimos dez anos muito mais qualitativamente do que quantitativamente. Se em 2010 a qualidade média da produção geomorfológica brasileira estava próxima ou era até superior à da Áustria ou Noruega, hoje ela é sensivelmente inferior (Figura 7).

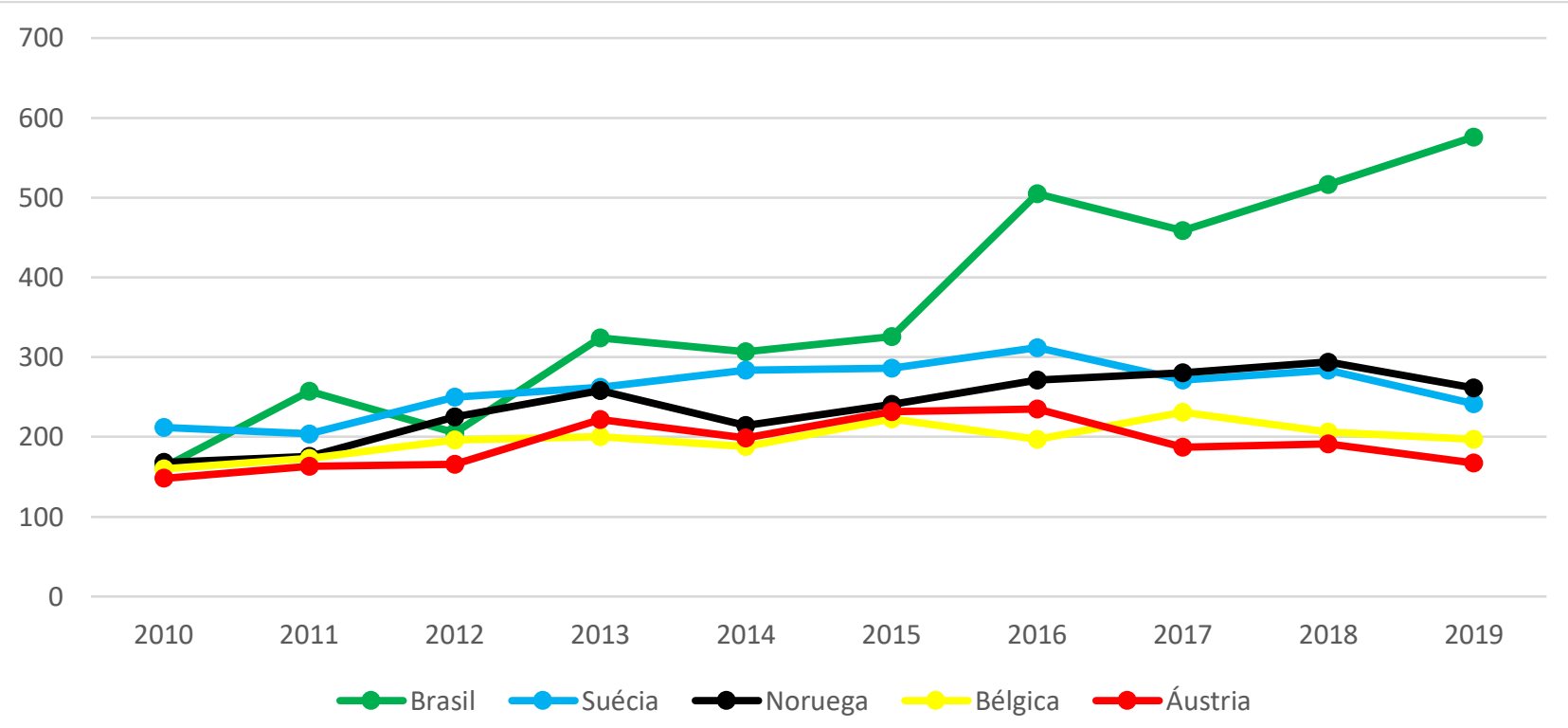

Figura 6: Evolução das publicações anuais de documentos científicos de Geomorfologia para os países que em 2010 ocupavam no ranking mundial posições semelhantes à do Brasil: Suécia, Noruega, Bélgica e Áustria.

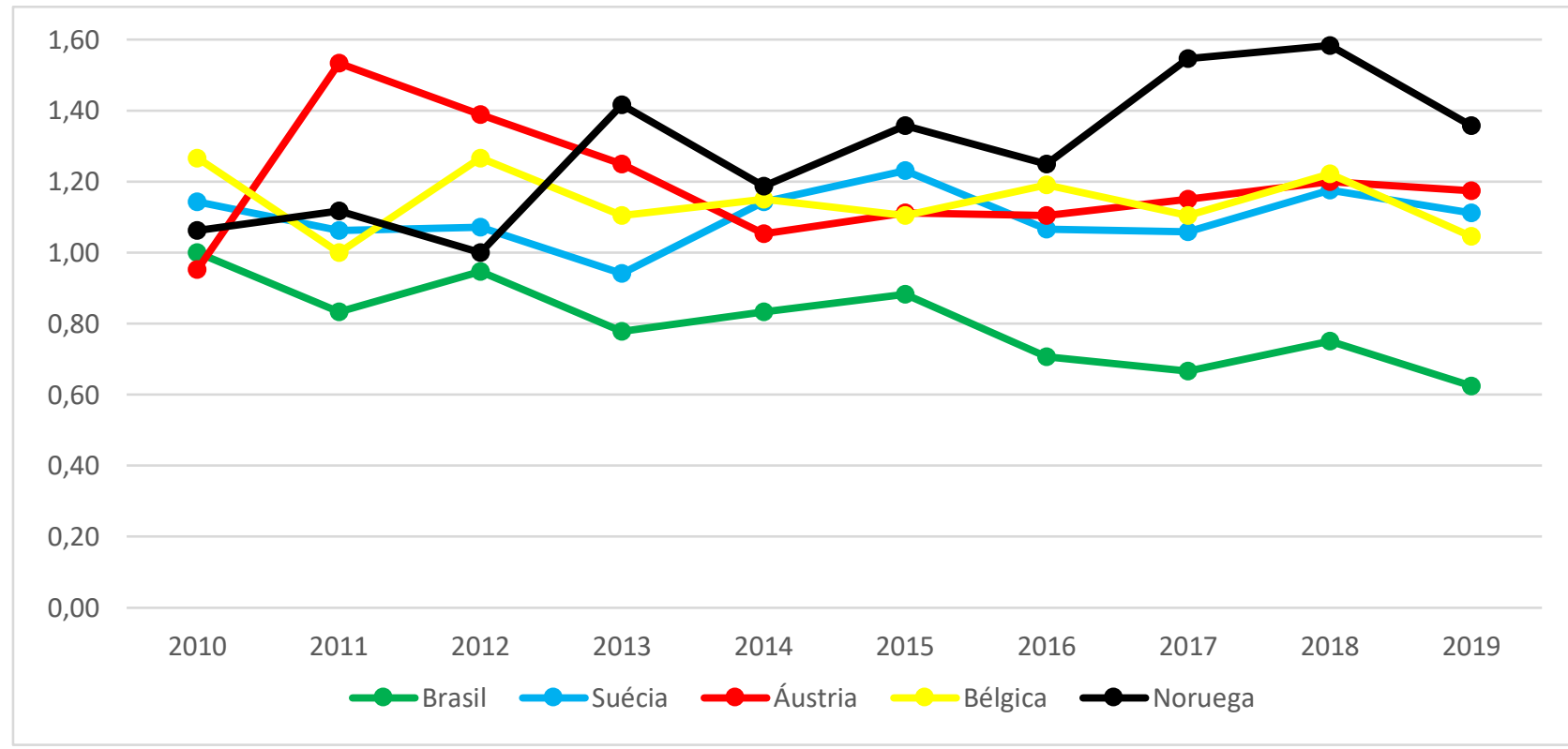

Figura 7: Evolução do índice $\boldsymbol{\alpha}$ (relação produção/citações) no ranking mundial de Geomorfologia para os países que em 2010 ocupavam posições semelhantes à do Brasil: Suécia, Noruega, Bélgica e Áustria.

4. DISCUSSÔES 
Entender por quais razões houve um aumento tão grande do número de artigos de Geomorfologia no Brasil e por qual razão as citações não se incrementaram no mesmo patamar não é tarefa fácil. Uma série de questões políticas, sociais, financeiras e até emocionais dos pesquisadores podem estar envolvidas. Além disso, mesmo que fosse possível identificar todas as razões, provar cientificamente as relações de causa e efeito permaneceria praticamente impossível, pois a análise envolve fatores psicossociais e estes, cientificamente, são sempre de difícil comprovação e praticamente impermeáveis a testes empíricos (Merton, 1973; Oliva, 2003). Logo, as discussões visam muito mais levantar hipóteses que possam explicar o fenômeno do que determinar por qual razão ocorreu esta dissociação entre quantidade e qualidade na produção geomorfológica brasileira entre 2010-2019.

Neste caminho, em primeiro lugar é necessário deixar claro que não há dúvidas que o Brasil, ao longo dos últimos dez anos, em termos quantitativos, expandiu muito sua produção de conhecimento geomorfológico (Tabelas 1, 2 e 3 e figuras 4 e 6). Esta produção mais do que triplicou durante este período. Entretanto, também não restam dúvidas que esta expansão não gerou um igual incremento no número de citações (Figuras 3, 5 e 7). Logo, ao menos em termos relativos, enquanto houve uma robusta expansão no número de artigos publicados, houve em média um decréscimo na qualidade do que foi publicado. De fato, hoje o Brasil produz muito mais conhecimento geomorfológico do que produzia dez anos atrás, mas obtêm, comparativamente, muito menos citações em média por artigo publicado. Em termos da relação produção/citação, pode ser afirmado que a qualidade média dos atuais documentos científicos publicados é de apenas $63 \%$ do que era dez anos atrás (índice $\boldsymbol{\alpha}$ 0,63 nas tabelas 1, 2 e 3 e nas figuras 3,5 e 7). Isto não significa que tenha sido ruim ter expandido a produção de artigos geomorfológicos no Brasil. Pelo contrário: este movimento de expansão é global e saudável. Quase todos os países do mundo expandiram sua produção de conhecimento, embora o tenham feito em intensidades variáveis (Tabelas 2 e 3). Logo, a Geomorfologia brasileira merece ser felicitada por essa expansão. Porém, o que ocorreu é que esta expansão foi muito mais acelerada do que no resto do mundo, tanto que o país saltou oito posições no ranking mundial de produção de documentos geomorfológicos (Tabelas 1, 2 e 3). Neste ponto reside o problema, pois foi pago um preço elevado neste processo, visto ter havido uma perda na qualidade média das publicações.

No que concerne aos nossos vizinhos, os países latino-americanos apresentaram, em geral, tendência semelhante à do Brasil (Figuras 4 e 5). Porém, o Brasil é o país que 
mais se destacou no que se refere ao elevado número de produções. Isto evidencia que houve algo interno ao país levando-o a aumentar significativamente a produção de artigos sem impactar proporcionalmente o número de citações. Também sugere que algo em comum afetou os países latino-americanos analisados, uma vez que à exceção da Argentina que se manteve estacionária, todos pioraram o índice $\boldsymbol{\alpha}$ nos últimos dez anos. Em paralelo, o fato de nenhum dos países europeus analisados ter acompanhado claramente o comportamento brasileiro (Figuras 4, 5, 6 e 7), sugere que os fatores que determinaram a evolução da Geomorfologia brasileira nos rankings mundiais foram, em algum grau, realmente internos ao país. Entretanto, nem a Ciência brasileira como um todo, nem sua grande área das Geociências acompanharam esta tendência de rápido crescimento quantitativo dissociado de melhora qualitativa (Figuras 2 e 3). Logo, e considerando que a Geomorfologia brasileira é dominada por pesquisadores da Geografia (Soares et al., 2012), é possível supor que foram fatores internos a essa área que explicam a dissociação entre quantidade e qualidade na produção de conhecimento geomorfológico no Brasil durante o período analisado. Por consequência, será na Geografia brasileira que devem se procuradas as respostas para o crescimento quantitativo dissociado de um desenvolvimento qualitativo.

É absolutamente normal que com o passar do tempo a produção do conhecimento se expanda. Idealmente, essa expansão deve alimentar uma melhora gradativa do ensino em um processo que se retroalimenta, pois um melhor ensino tende a permitir uma constante evolução da produção do conhecimento, tanto quantitativamente, quanto qualitativamente. Logo, se a qualidade da produção não segue este processo de constante melhoria, há um problema que precisa ser sanado e que de alguma forma deve ou deverá se refletir no Ensino. No entanto, na Geomorfologia brasileira houve uma expansão quantitativa tão rápida da produção de documentos científicos que se discute não uma estagnação qualitativa, mas sim um retrocesso. Em dez anos mais do que triplicou a produção geomorfológica brasileira, sem, no entanto, ter havido um real incremento na quantidade de citações ou na posição do país no ranking mundial de citações (tabelas 1, 2 e 3 e figuras 1, 4,5,6 e 7).

A primeira hipótese que explica esta situação está na expansão do ensino universitário no Brasil. Na relação Ensino/Pesquisa deve-se considerar que a Geografia acadêmica brasileira viveu uma rápida expansão desde 2007. Foram muitos os cursos de graduação e pós-graduação abertos em instituições públicas de ensino e isto, consequentemente, se refletiu na quantidade de sua produção científica. Por exemplo, em 
2008 o Brasil tinha 36 programas de pós-graduação em Geografia (CAPES, 2019). Em 2019 já tinha mais que o dobro: 76. Sendo assim, o comportamento de expansão da pósgraduação em Geografia no Brasil é compatível com o do crescimento da produção de documentos em Geomorfologia (Tabela 1). Muitos mais doutores empregados e doutorandos e mestrandos pesquisando geraram um natural crescimento da produção científica. Ademais, soma-se ao efeito expansivo da Geografia na academia brasileira, o crescimento dos institutos federais de ensino que também abrigaram geógrafos de diversas áreas da Geografia e assim colaboraram para a ampliação da produção científica brasileira na área de Geomorfologia. Logo e considerando que a maior parte dos geomorfólogos brasileiros são geógrafos e/ou oriundos de cursos de pós-graduação em Geografia (Soares et al., 2012), fica difícil não relacionar a massiva expansão da produção de artigos geomorfológicos brasileiros com a massiva expansão de cursos e vagas de Geografia nas instituições de ensino e pesquisa públicas brasileiras neste início de século. Como dito anteriormente isto não seria um problema se o crescimento da produção científica geomorfológica no Brasil não tivesse ocorrido desacoplado de um crescimento do número de citações (Tabela 1 e Figura 1). Deste modo, esta hipótese considera que a acelerada expansão quantitativa de pesquisadores causou um aumento da produção, mas, em média, uma piora qualitativa daquilo que era produzido.

A segunda hipótese não está dissociada da primeira e se refere aos recursos financeiros necessários para realizar uma boa pesquisa científica. É bem verdade que produzir conhecimento geomorfológico relevante se tornou algo cada vez mais oneroso (Salgado e Martins, 2020). Isto talvez explique o fato de, comparativamente ao restante do globo, a qualidade média do que foi produzido na América Latina ter decaído (Figura 5), enquanto os ricos países europeus que em 2010 se situavam próximos ao Brasil no ranking mundial terem até melhorado seus índices a (Figura 7). Em paralelo, mais pesquisadores quase sempre significa mais pesquisas e, por consequência, uma maior necessidade de recursos financeiros. Logo, crescer a produção e manter a qualidade do que foi produzido exige mais dinheiro nas duas frentes: tanto por ser necessário gastar mais por pesquisa, quanto por haver mais pesquisas exigindo financiamento. Como dito acima, os investimentos necessários para se produzir e publicar um bom artigo em Geomorfologia, que gere muitas citações, são cada vez maiores e por isso os países desenvolvidos, à exemplo da Suécia, Bélgica, Noruega e Áustria, têm mais facilidade para manter a qualidade de sua produção. Neste contexto, o decréscimo da qualidade média do que foi produzido no Brasil é algo até esperado. O comportamento de toda a América 
Latina (Figura 5) corrobora esta expectativa. No entanto, este decréscimo no Brasil foi mais acentuado que no restante da América Latina e o aumento dos custos necessários para se produzir conhecimento de qualidade não aumentaram apenas para a Geomorfologia. Eles também aumentaram para as Geociências em geral e no Brasil esta área do conhecimento não apresentou perda de qualidade média de sua produção (Figura 3). Logo, houve sim, para além das dificuldades econômicas, outros fatores que colaboraram para o decréscimo da qualidade média da produção geomorfológica brasileira. Sendo assim, é possível supor que, ao menos para a Geomorfologia, as questões financeiras não são as únicas que explicam o fenômeno diagnosticado.

A terceira hipótese baseia-se no fato de que a dissociação quantidade/qualidade da produção geomorfológica brasileira teve origem na forte expansão do número de periódicos geográficos nacionais, alguns muito bem avaliados pelo sistema Qualis CAPES (CAPES, 2021). Desde o início do século XXI houve um claro incentivo à produtividade científica e estes periódicos nacionais bem avaliados no Qualis CAPES, mas com pouco fator de impacto na Ciência internacional, receberam muitos artigos de Geomorfologia. Nesse cenário, para os professores, doutorandos, mestrandos e até graduandos em Geografia no Brasil ficou interessante publicar nos periódicos nacionais, pois além de numerosos, muitos eram bem avaliados pela área da Geografia pela CAPES. Logo, o sistema de pontuação do Qualis CAPES Geografia incentivou a publicação em revistas nacionais. O problema é que, globalmente, estes periódicos nacionais não têm quase nenhum impacto. Praticamente, apenas os pesquisadores brasileiros e alguns lusófonos os leem. Isto reduz severamente o número de citações que os artigos publicados irão receber. Já nas Geociências ocorreu processo contrário, pois nesta área os periódicos nacionais foram desvalorizados nos Qualis CAPES (CAPES, 2021) e por isso os pesquisadores cada vez mais procuraram os jornais internacionais com alto fator de impacto para divulgar suas pesquisas. Reforça esta hipótese o fato que, ao menos entre 2010 e 2015, não foi possível verificar nenhum tipo de expansão quantitativa da produção geomorfológica brasileira nos periódicos internacionais de Geomorfologia (Oliveira e Salgado, 2013; Salgado e Limoeiro, 2017). Esta hipótese ainda explicaria as diferentes tendências apresentadas pela produção do conhecimento na Geomorfologia e nas Geociências brasileiras (Tabela 1 e Figura 3).

De fato, os periódicos nacionais praticamente só publicam no idioma português, sendo em sua maioria lidos no Brasil e não têm a mesma visibilidade e impacto que os internacionais. A multiplicação de artigos publicados neles provavelmente contribuiu para 
uma dissociação entre produção/citações na Geomorfologia brasileira (Tabela 1, 2 e 3 e figuras 3, 5 e 7). Se um novo Qualis CAPES Geografia passar a valorizar de fato a produção internacional, ou seja, aquela que pode ser lida e referenciada em pesquisas por todo globo, é possível que parte considerável dos pesquisadores brasileiros procurem se adaptar à nova situação. O comportamento das Geociências reforça essa expectativa, pois essa área reservou os patamares mais elevados do seu Qualis CAPES para os periódicos internacionais com alto fator de impacto (CAPES, 2021) e, mesmo sendo uma Ciência onde produzir conhecimento requer gastos elevados, conseguiu manter o equilíbrio entre produção/citações de artigos (Tabela 1 e Figura 3).

Neste contexto, e considerando que os periódicos nacionais, ao menos os mais relevantes, procuraram ter um número $\mathrm{DOI}$, fato que os tornou passíveis de serem acompanhados pelos sites e organizações internacionais que contabilizam a produção científica, a melhor resposta para o aumento quantitativo com perda qualitativa da produção geomorfológica nacional, a que conjuga as três hipóteses, residiria na rápida expansão: (1) do número de docentes e discentes (graduação e pós-graduação) em instituições federais de ensino; (2) dos custos financeiros para executar uma boa pesquisa científica em Geomorfologia e; (3) do número de periódicos brasileiros. Em outras palavras, é possível que a causa do problema se relacione a um número crescente de pesquisadores em instituições públicas, com poucos recursos para pesquisa, tendo facilidade de obter um alto Qualis CAPES redigindo em português e publicando em revistas nacionais de baixo impacto.

\section{CONSIDERAÇÕES FINAIS}

Procurando mensurar a relação entre o crescimento quantitativo e qualitativo da produção de conhecimento geomorfológico no Brasil e considerando o número de citações como caminho encontrado para se verificar a qualidade das publicações, os resultados encontrados permitiram constatar que houve um expressivo crescimento da produção de artigos dissociada do número de citações. Esse crescimento não ocorreu de maneira semelhante para a área das Geociências e para a Ciência brasileira como um todo, que se mantiveram constantes na evolução da produção de documentos científicos e com leve crescimento qualitativo na relação entre produção e número de citações.

Considerando que as causas para este fenômeno devem residir em uma série de fatores que vão desde a política ao emocional dos pesquisadores, passando por questões, sociais e financeiras, torna-se impossível explicar por qual razão houve no 
Brasil durante o período estudado um expressivo crescimento da produção de artigos científicos de Geomorfologia dissociada de um crescimento no número de citações. Entretanto, hipóteses puderam ser formuladas. Estas incluem o fato de que produzir e publicar conhecimento de impacto na Geomorfologia se tornou muito oneroso. Isto fez com que toda a América Latina tenha tido uma perda qualitativa em sua produção, enquanto países mais ricos da Europa conseguiram manter a qualidade do que produziam. Entretanto, no Brasil o fenômeno foi muito mais intenso e parece estar, ao menos parcialmente, relacionado a uma segunda hipótese: a rápida e expressiva expansão do sistema público de ensino nos níveis de graduação e pós-graduação em Geografia.

Por fim, levantou-se uma terceira e última hipótese: de que o sistema de avaliação da Geografia brasileira, o Qualis CAPES, também colaborou com a perda da qualidade da produção geomorfológica brasileira, pois esse sistema pontua muito bem algumas revistas nacionais que não possuem real impacto internacional. Isto, aliado a forte expansão do número de periódicos geográficos brasileiros, teria favorecido aos pesquisadores de todos os níveis o direcionamento da sua produção científica para revistas sem repercussão ou impacto internacional. Logo, para esta hipótese o sistema avaliativo diminuiu a qualidade média da produção brasileira em Geomorfologia, pois se tornou mais vantajoso publicar em periódicos nacionais de baixo impacto, do que nos internacionais que são mais rigorosos e possuem maior repercussão.

\section{AGRADECIMENTOS}

Agradeço ao CNPq (Projeto 102176/2018-3) pelo apoio financeiro.

\section{REFERÊNCIAS}

CAPES. Documento de Área Geografia. 2019. 33p.

CAPES. Plataforma Sucupira. 2021. Disponível em: https://sucupira.capes.gov.br /sucupiral. Acesso em: 5 mai. 2021.

GOOGLE ACADÊMICO. 2021. Disponível em: https://scholar.google.com.br/2021. Acesso em: 5 mai. 2021.

JOURNAL CITATION REPORTS. Journal Citation Reports. Science Edition. London: Thomson, 2020. 
MERTON, R. K. The Sociology of Science. Chicago: The University of Chicago Press Books, 1973. 662p.

OLIVA, A. Filosofia da Ciência. Rio de Janeiro: Editora Zahar, 2003. 85p.

OLIVEIRA, C. K. R.; SALGADO, A. A. R. Geomorfologia brasileira: panorama geral da produção nacional de alto impacto no quinquênio entre 2006-2010. Revista Brasileira de Geomorfologia, Brasília, v. 14, n. 1, p. 117-123, 2013.

SALGADO, A. A. R.; LIMOEIRO, B. Geomorfologia brasileira: panorama geral da produção nacional de alto impacto no quinquênio entre 2011-2015. Revista Brasileira de Geomorfologia, Brasília, v. 18, n. 1, p. 225-236, 2017.

SALGADO, A. A. R.; MARTINS, F. P. A elite da elite: a aplicação do Princípio de Pareto na análise da produção brasileira de conhecimento geográfico de impacto internacional. Caderno de Geografia, v. 30, n. 63, p. 1183-1194, 2020.

SJR - Scimago Journal \& Country Rank. 2021. Disponível em: https://www.scimagojr. com/countryrank.php?category=1904\&area $=1900 \& y e a r=2019 \& o r d e r=c d \& o r d=d e s c \& m i n=$ 100\&min type=it. Acesso em: 15 abr. 2021.

SOARES, W.; SALGADO, A. A. R.; OLIVEIRA, C. K. R. Geomorfologia brasileira: Ciência Interdisciplinar. Revista Brasileira de Geomorfologia, Brasília, v. 13, n. 3, p. 351-354, 2012. 